The Cryosphere, 2, 23-31, 2008

www.the-cryosphere.net/2/23/2008/

(C) Author(s) 2008. This work is distributed under

the Creative Commons Attribution 3.0 License.

\title{
Modelling historical and recent mass loss of McCall Glacier, Alaska, USA
}

\author{
C. Delcourt ${ }^{1}$, F. Pattyn ${ }^{1}$, and M. Nolan ${ }^{2}$ \\ ${ }^{1}$ Laboratoire de Glaciologie, Département des Sciences de la Terre et de l'Environnement, Université Libre de Bruxelles, CP \\ 160/03, Avenue F.D. Roosevelt 50, 1050 Brussels, Belgium \\ ${ }^{2}$ Institute of Northern Engineering, 455 Duckering Bldg, University of Alaska Fairbanks, AK, USA
}

Received: 17 October 2007 - Published in The Cryosphere Discuss.: 5 November 2007

Revised: 25 January 2008 - Accepted: 13 February 2008 - Published: 18 March 2008

\begin{abstract}
Volume loss of valley glaciers is now considered to be a significant contribution to sea level rise. Understanding and identifying the processes involved in accelerated mass loss are necessary to determine their impact on the global system. Here we present results from a series of model experiments with a higher-order thermomechanically coupled flowline model (Pattyn, 2002). Boundary conditions to the model are parameterizations of surface mass balance, geothermal heating, observed surface and $10 \mathrm{~m}$ ice depth temperatures. The time-dependent experiments aim at simulating the glacier retreat from its LIA expansion to present according to different scenarios and model parameters. Model output was validated against measurements of ice velocity, ice surface elevation and terminus position at different stages. Results demonstrate that a key factor in determining the glacier retreat history is the importance of internal accumulation $(>50 \%)$ in the total mass balance. The persistence of a basal temperate zone characteristic for this polythermal glacier depends largely on its contribution. Accelerated glacier retreat since the early nineties seems directly related to the increase in ELA and the sudden reduction in AAR due to the fact that a large lower elevation cirque previously an important accumulation area - became part of the ablation zone.
\end{abstract}

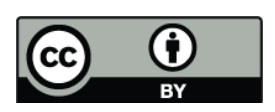

Correspondence to: C. Delcourt

(cdelcour@ulb.ac.be)

\section{Introduction}

McCall Glacier is situated at $69^{\circ} 18^{\prime} \mathrm{N}, 143^{\circ} 48^{\prime} \mathrm{W}$, in the northeastern part of the Brooks Range, Alaska. The glacier is $\sim 7.6 \mathrm{~km}$ long, $120 \mathrm{~m}$ thick and covers an area of $6 \mathrm{~km}^{2}$ (Fig. 1). It extends from an altitude of $2500 \mathrm{~m}$ down to $1365 \mathrm{~m}$ at the terminus, with an equilibrium line altitude (ELA) between 2000 to $2400 \mathrm{~m}$ (Nolan et al., 2005). McCall Glacier is known to be a polythermal glacier, with a temperate basal layer along a section of the lower glacier (Pattyn et al., 2005). The glacier has been studied extensively, from IGY (1957-1958) onwards through to the International Hydrological Decade (1969-1972) and the mid 1990s to present. These studies have shown that McCall Glacier has been losing mass for decades, accelerating over the last 10 to 20 years (Rabus et al., 1995; Nolan et al., 2005). Moreover, it seems that this well-studied glacier is representative of the other large glaciers of its region (Rabus and Echelmeyer, 1998). Hence, McCall Glacier is considered as a good indicator for climate change in the Arctic (Nolan et al., 2005), situated in an area sensitive to climate change (IPCC, 2007).

In this paper we will try to disentangle the mechanisms responsible for the general and accelerated retreat of McCall Glacier using both a higher-order and a shallow-ice thermomechanical glacier model. Simulated retreat will be compared with field observations, such as time series of ice velocity, ice thickness and terminus position.

Published by Copernicus Publications on behalf of the European Geosciences Union. 


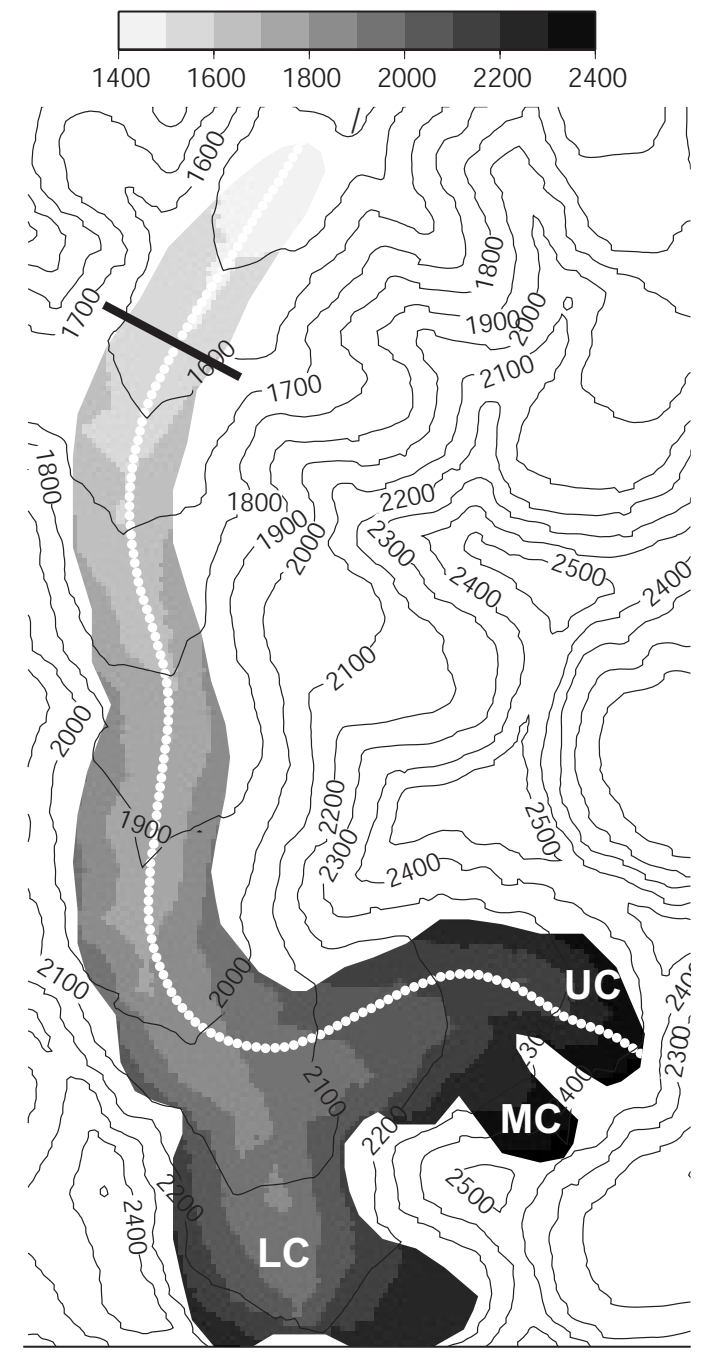

Fig. 1. Surface (contours) and subglacial (gray-shaded) topographic map of McCall Glacier. The modeled flowline is shown in white. LC, MC and UC indicate Lower Cirque, Middle Cirque and Upper Cirque, respectively. The upper transverse profile (or upper transect) is shown in black. Map compiled from existing and new ice thickness measurements (Pattyn et al., 2008 ${ }^{1}$ ).

\section{Glacier model}

The higher-order glacier model (HOM) is based on conservation laws of energy, mass and momentum and solves the velocity and stress field along a fixed flowline in space and time, taking into account longitudinal stress gradients (Pattyn, 2002). Approximations to the Stokes system involve hydrostatic pressure in the vertical (neglecting the so-called bridging effect) as well as neglecting horizontal gradients of the vertical velocity in the effective strain rate. Hence, the force balance reads:

$2 \frac{\partial \sigma_{x x}^{\prime}}{\partial x}+\frac{\partial \sigma_{x z}}{\partial z}=\rho g f \frac{\partial z_{s}}{\partial x}$, where $\sigma_{x z}$ is the vertical shear stress and $\sigma_{x x}^{\prime}$ the longitudinal deviatoric normal stress, $\rho$ is the ice density, $g$ is the gravitational constant, $z_{s}$ is the surface of the ice mass, and $f$ a shape factor to account for valley-wall friction, determined by considering a parabola-shaped valley cross-section for each grid point along the flowline according to the method described in Paterson (1994).

The constitutive equation governing the creep of polycrystalline ice and relating the deviatoric stresses to the strain rates, is taken as a Glen-type flow law with exponent $n=3$ (Paterson, 1994), with a temperature dependent flow rate factor $A\left(T^{*}\right)$ obeying an Arrhenius relationship (Pattyn, 2002):

$A\left(T^{*}\right)=a \exp \left(-\frac{Q}{R T^{*}}\right)$,

where $a=1.14 \times 10^{-5} \mathrm{~Pa}^{-n} \mathrm{a}^{-1}$ and $Q=60 \mathrm{~kJ} \mathrm{~mol}^{-1}$ for $T^{*}<263.15 \mathrm{~K}, a=5.47 \times 10^{10} \mathrm{~Pa}^{-n} \mathrm{a}^{-1}$ and $Q=139 \mathrm{~kJ} \mathrm{~mol}^{-1}$ for $T^{*} \geq 263.15 \mathrm{~K} . \quad R$ is the universal gas constant $\left(8.314 \mathrm{~J} \mathrm{~mol}^{-1} \mathrm{~K}^{-1}\right)$ and $T^{*}$ is the corrected temperature for the dependence of the melting point on pressure (Pattyn, 2002).

Heat transfer is included in the model and is a result of vertical diffusion, horizontal and vertical advection, and internal friction due to deformational heating. When ice reaches pressure melting temperature, the ice temperature is kept constant at this value. Some of the experiments described below are based on an isothermal glacier, in which $A\left(T^{*}\right)$ is kept constant over the whole domain. All experiments with the higher-order model (HOM) were furthermore compared to a similar model according to the shallow-ice approximation (SIA), in which ice velocities are determined from local geometric glacier characteristics (e.g. Huybrechts, 1992):

$u(z)-u_{b}=\frac{2 A\left(T^{*}\right)}{n+1}\left(\rho g \frac{\partial z_{s}}{\partial x}\right)^{n}\left[\left(z_{s}-z\right)^{n+1}-H^{n+1}\right]$

where $H$ is the ice thickness and $u_{b}$ is the velocity at the base of the glacier. Time-dependent evolution of the ice thickness is given by the following relation:

$\frac{\partial H}{\partial t}=M-\frac{1}{W} \frac{\partial(\bar{u} H W)}{\partial x}$,

where $\bar{u}$ is the vertical mean horizontal velocity, $M$ is the surface mass balance ( $\mathrm{m} \mathrm{a}^{-1}$ water equivalent), and $W(\mathrm{~m})$ is the width of the glacier perpendicular to the flowline. The latter allows to take into account convergence and divergence of the ice flow along the flowline, hence the three-dimensional nature of the domain.

\section{Boundary conditions and input data}

Basic input to the flow model is the longitudinal profile along the central flowline of McCall Glacier. Surface elevation was measured with digital GPS (Nolan et al., 2005), while 
bedrock elevation was derived from ice thickness measurements, both carried out during several field seasons between 2003 and 2006 (Fig. 1; Pattyn et al., 2008 ${ }^{1}$ ). The central flowline runs from the head of the Upper Cirque (UC) to the front of the glacier (and the valley downstream) with a spatial interval of $50 \mathrm{~m}$. Preliminary experiments were carried out in which the Lower (LC) and the smaller Middle Cirque (MC) were taken into account as well in the width paramater $W$. Although the qualitative behaviour of the model remained the same for both types of parameterization, the divergence of the ice flow was overestimated, hence leading to unrealistic values with such a simple approach. Therefore, the experiments presented in this paper account for the width variations along the glacier for the main trunc, starting at the Upper Cirque. Future model attempts with a full three-dimensional glacier model should shed more light on this.

Surface mass balance was measured over several periods (1969-1972, 1993-1996 and 2003-2004). A linear relation between the altitude and the surface mass balance was found over the glacier for the first two periods by Rabus and Echelmeyer (1998) and the trend of the 2003-2004 measurements obey a linear relationship as well (Fig. 2). The mass balance gradient was therefore determined as a mean of the three gradients in Fig. 2, so that the mass balance parameterization becomes

$M=0.0017 \times\left(z_{s}-\mathrm{ELA}\right)$,

where ELA is the equilibrium-line altitude.

The mean ELA was determined for different periods, i.e. $2055 \mathrm{~m}$ for the 1970s and $2250 \mathrm{~m}$ for the mid 1990s (Rabus and Echelmeyer, 1998). For the season 2003-2004, the ELA is estimated to lie between 2000 and $2400 \mathrm{~m}$ (Nolan et al., 2005). However, the LC, culminating at $2250 \mathrm{~m}$, is believed to form part of the ablation area since the late 1990s. Therefore, we assume the ELA above $2300 \mathrm{~m}$ in 2005.

Internal accumulation is a key process on McCall Glacier, and consists of percolation and refreezing of surface meltwater into the ice mass. For McCall Glacier this represents more than half of the annual net accumulation, i.e. $50 \%$ in the 1970 s, $65 \%$ in the 1980 s and almost $100 \%$ in the 1990 s (Trabant and Mayo, 1985; Rabus and Echelmeyer, 1998). It plays an essential role in the redistribution of mass from the surface to the interior of the glacier and increases the mass balance of the accumulation area (Trabant and Mayo, 1985). Internal accumulation has also important consequences for the temperature of the ice mass. The $10 \mathrm{~m}$-depth ice temperatures in the accumulation zone of the glacier are higher than these of the ablation area, despite a higher altitude. They are attributed to latent-heat release due to the refreezing process of meltwater in the accumulation zone.

\footnotetext{
${ }^{1}$ Pattyn, F., Delcourt, C., Samyn, D., De Smedt, B., and Nolan, M.: Bed properties and hydrological conditions underneath McCall Glacier, Alaska, USA, Ann. Glaciol., in preparation, 2008.
}

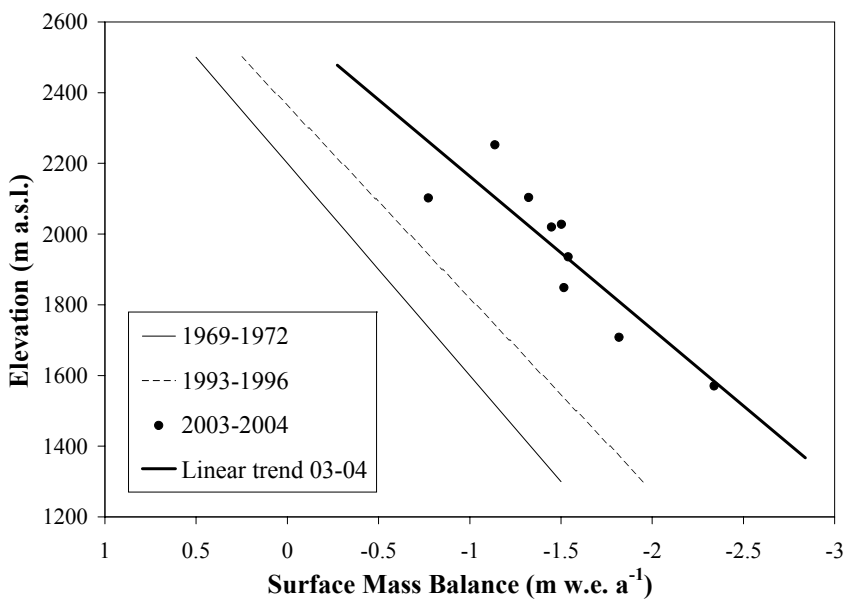

Fig. 2. Surface mass balance as a function of elevation for the periods 1969-1972, 1993-1996 (digitized from Rabus and Echelmeyer, 1998) and 2003-2004 (field measurements from Nolan, unpublished data).

The computed temperature field is bounded by the geothermal heat at the base and the $10 \mathrm{~m}$-depth temperature at the surface. The basal temperature gradient is defined by

$\frac{\partial T}{\partial z}=-\frac{G}{K}$,

where $G$ is the geothermal heat flux, estimated as $0.06 \mathrm{~W} \mathrm{~m}^{-2}$ from Shapiro and Ritzwoller (2004), $K$ is the thermal conductivity, dependent on temperature $(T)$ (Paterson, 1994):

$K=9.828 \times \exp (0.0057 \times T)$.

For the ablation area, seasonal variations in surface temperature are limited to a layer of $<10 \mathrm{~m}$, which is used as the upper boundary condition for the temperature field. Based on the measurements of Rabus and Echelmeyer (2002), $10 \mathrm{~m}$ ice temperatures in the ablation area were parameterized as a linear function of altitude. However, in the accumulation area, surface temperatures are perturbed by latent heat release due to melting and refreezing processes. This leads to more or less isothermal conditions, and mean annual temperatures are around $-6.3^{\circ} \mathrm{C}$ (Rabus and Echelmeyer, 2002). Therefore, surface temperatures are defined as:

$T_{s}= \begin{cases}-2.08-0.00335 z_{s} & \text { in the ablation zone } \\ -6.3 & \text { in the accumulation zone }\end{cases}$

Such treatment inevitably leads to a sudden break of $\sim 2^{\circ} \mathrm{C}$ in the surface temperature at the ELA, but this discontinuity dissipates with depth as can be seen in Fig. 3. This operation softens the ice in the accumulation area to obtain more realistic simulated surface velocities and ice thicknesses. According to temperature measurements, ice in the accumulation area may be considered isothermal over its whole thickness 

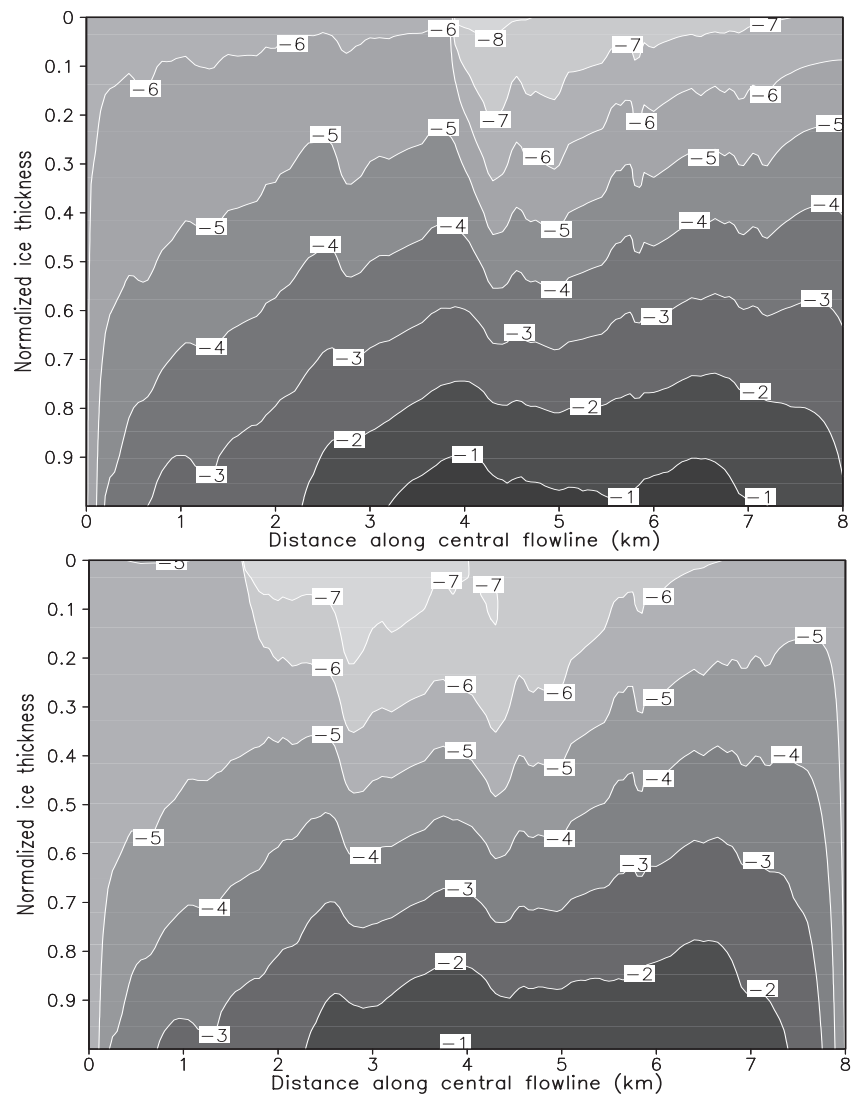

Fig. 3. Vertical temperature field corrected for the dependence on pressure melting along the flowline for the simulated LIA glacier (top) and for the time-dependent model run (Exp. E) in 1980 (bottom). The ELA is marked by the discontinuity in surface temperature.

(Rabus and Echelmeyer, 2002). Although not parameterized as such, our model experiments demonstrate the existence of a quasi isothermal ice layer in the accumulation area once the glacier is in a transient state (Fig. 3), so that the crude approximation of latent heat release may hold.

Boundary conditions to the velocity field are a stress-free surface, while at the base a basal sliding function is introduced through a friction coefficient $\beta^{2}$, so that $\tau_{b}=u_{b} \cdot \beta^{2}$, where

$\beta^{2}=\left(\frac{N}{A_{s}} \exp \left[\gamma\left(T_{\mathrm{pmp}}-T_{b}\right)\right]\right) \tau_{b}^{1-p}$.

$N$ is the effective pressure at the base of the ice mass, approximated by the ice overburden pressure $(N \approx \rho g H$; Pattyn, 2002), $A_{s}$ is a sliding coefficient, $T_{\mathrm{pmp}}$ and $T_{b}$ are the pressure melting and basal ice temperature, respectively, and $p=3$ is the sliding law power coefficient. Basal sliding occurs whenever the pressure melting point is reached within a range of $\gamma=1 \mathrm{~K}$.

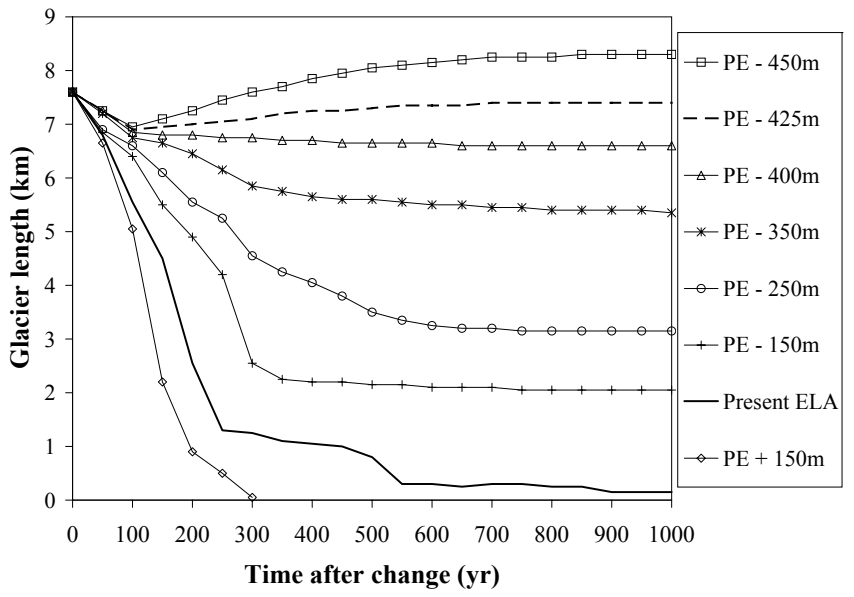

Fig. 4. Evolution of McCall Glacier with time, starting from present-day observed geometry, according to different ELA perturbations. Present ELA equals $2350 \mathrm{~m}$ a.s.1.

\section{Model results}

\subsection{Glacier sensitivity experiments}

The first goal of this study is to have a general view of the dynamic behavior of the glacier through a set of sensitivity experiments of the response of McCall Glacier to a sudden change in climate. Starting from the present-day observed glacier geometry, different ELA perturbations were applied and the model was run forward until a steady state was reached (Fig. 4). For this series of experiments, $A\left(T^{*}\right)$ was kept constant at $10^{-16} \mathrm{~Pa}^{-n} \mathrm{a}^{-1}$.

From Fig. 4 it is obvious that under present-day ELA conditions McCall Glacier would largely disappear in less than 300 years. Considering a future rise in ELA leads to a faster wastage of the glacier at terminus retreat rates up to $5 \mathrm{~km}$ per century. To maintain the current length of the glacier under steady state conditions, a lowering of the ELA of more than $400 \mathrm{~m}$ is required. This demonstrates that the glacier is definitely in a transient state, responding to present as well as past climate changes. However, during the 1950s the glacier surface was close to the height of the Little Ice Age (LIA) lateral moraines (at least for the part away from the terminus), while the glacier terminus was situated approximately $300 \mathrm{~m}$ from the LIA end moraine (Rabus et al., 1995), as corroborated by historic photographs (Fig. 5). This points to relatively stable conditions at the end of the LIA.

\subsection{Reconstructing the LIA glacier}

The last major advance of the glaciers at Brooks Range ended in 1890 (Nolan et al., 2005). For McCall Glacier a terminal moraine, located $800 \mathrm{~m}$ downstream from the present terminus, is attributed to the last glacier advance corresponding to the LIA. This moraine, dated by lichonometry, suggests that 


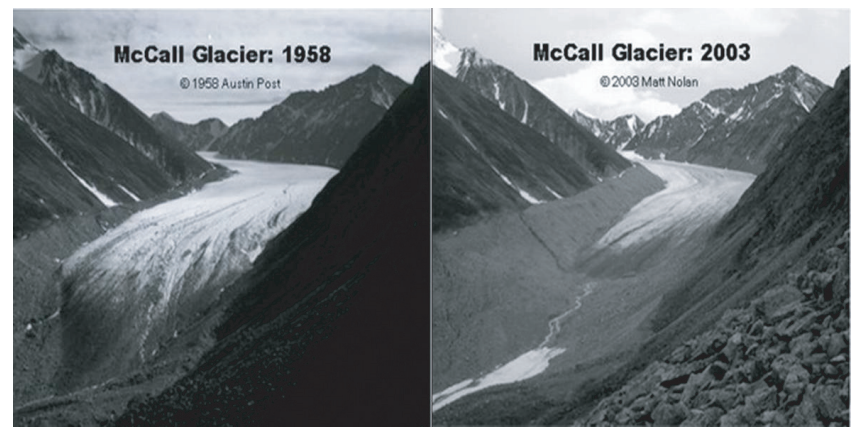

Fig. 5. Comparison of McCall Glacier terminus in 1958 (left) and 2003 (right), from Nolan et al. (2005).

the end of the 19th Century was a colder and more stable climatic period. We can therefore assume that the glacier was more or less in steady state at that time. In order to obtain these conditions, the ELA was lowered by $450 \mathrm{~m}$ to reach an elevation of $1900 \mathrm{~m}$ a.s.l. (equivalent to an increase in AAR from $<0.1$ to $\sim 0.6$ ). Internal accumulation was not taken into account for this experiment, but accounted for in some of the retreat experiments, as is discussed below.

The modeled LIA profile was validated against surface elevation measurements of two cross sections studied since the 1950s: the lower transect (ice free today) and the upper transect (Fig. 1). At the upper transect, the LIA simulation gives an ice thickness of about $160 \mathrm{~m}$ while the reconstitution of this ice thickness based on moraine heights gives $168 \pm 10 \mathrm{~m}$ (Nolan et al., 2005). Furthermore, the simulated temperature profile shows a quasi temperate zone located around $\mathrm{km} \mathrm{4-5}$ of the longitudinal profile (Fig. 3, top). Radio-echo sounding (RES) measurements suggest that this is precisely the zone where basal sliding occurs (Pattyn et al., 2005). We may assume that the temperature field has not changed dramatically since the end of the LIA, as accelerated thinning of McCall Glacier did not begin before the 1970s. The period since then is much shorter than the time needed for the temperature field to reach steady state by thermal diffusion (on the order of $10^{2}$ years; Pattyn et al., 2005).

Since both ice thickness and basal temperatures reconstructions are in accordance with field observations, this geometry will form the base for each of the experiments to reconstruct the retreat history of McCall Glacier, according to different parameter settings.

\subsection{Retreat experiments}

Starting from the LIA conditions, the model ran forward in time (until 2010) according to the imposed environmental conditions. Model runs were carried out for both HOM and SIA models and different sets of boundary conditions, as listed in Table 1. Perturbations consist of changes in ELA, background temperature, proportion of the internal accumu-
Table 1. List of retreat experiments. Crosses refer to applied boundary conditions.

\begin{tabular}{ccccc}
\hline $\begin{array}{c}\text { Retreat } \\
\text { Exp. }\end{array}$ & $\begin{array}{c}\text { ELA } \\
\text { Evolution }\end{array}$ & $\begin{array}{c}\text { Temperature } \\
\text { Evolution }\end{array}$ & $\begin{array}{c}\text { Internal } \\
\text { Accumulation }\end{array}$ & $\begin{array}{c}\text { Basal } \\
\text { Sliding }\end{array}$ \\
\hline A & + & & & \\
B & + & + & & \\
C & + & + & + & \\
D & + & + & + & + \\
E & + & + & + & + \\
\hline
\end{tabular}

lation in the total mass balance and basal sliding, and are detailed hereafter.

ELA evolution: The equilibrium line altitude (ELA) is a key parameter to the evolution of the ice mass. According to our previous simulation, the LIA glacier is defined by an ELA of $1900 \mathrm{~m}$ a.s.1. The ELA was $\sim 2055 \mathrm{~m}$ a.s.l. for the 1969-1972 period, $\sim 2250 \mathrm{~m}$ a.s.l. for the 1993-1996 period (Rabus and Echelmeyer, 1998) and we can assume that the ELA is above $2300 \mathrm{~m}$ a.s.l. for 2005 (Nolan et al., 2005). The perturbation in ELA evolution is therefore considered to be a two-step change in ELA rate, i.e. $+0.9 \mathrm{~m} \mathrm{a}^{-1}$ before 1970 and $+10 \mathrm{~m} \mathrm{a}^{-1}$ after 1970 , indicating the recent acceleration.

Temperature evolution: Over the same period, surface temperatures have changed as well. They not only have an impact on accumulation and ablation rates through the ELA, but influence the boundary conditions to the temperature field as well. Following temperature measurements in Alaska, warming was introduced as a one-step temperature increase of $1.2^{\circ} \mathrm{C}$ in 1975 (Rabus et al., 1995). Whether we use a one-step or a linear temperature increase has only limited effects on the temperature field in the glacier.

Internal accumulation: The phenomenon of refreezing of percolating meltwater in the accumulation area, as mentioned previously, was parameterized in the following way: Rabus and Echelmeyer (1998) inferred internal accumulation being $50 \%$ of the total accumulation in 1970. This value was spread out over the whole accumulation area and added to the surface accumulation, as defined in Fig. 2. It then results that internal accumulation becomes proportionally more important in time as the accumulation area decreases. However, after 2005 internal accumulation has only a limited effect on the glacier as a whole as the accumulation area becomes equally small.

Basal sliding: Basal sliding is introduced in the model by adjusting the basal friction coefficient in Eq. (9). For $\beta^{2}=\infty$, ice is frozen to the bed, otherwise $\beta^{2}$ is obtained by setting $A_{s}$ to $0.5 \times 10^{-8} \mathrm{~N}^{-2}$ $\mathrm{m}^{5} \mathrm{a}^{-1}$.

In summary, experiment A only takes into account the ELA evolution, experiments B to E are driven by ELA and temperature evolution, experiments $\mathrm{C}$ and $\mathrm{D}$ include internal accumulation and basal sliding, respectively, and experiment $\mathrm{E}$ includes all the parameters. Experiment B is taken as the 


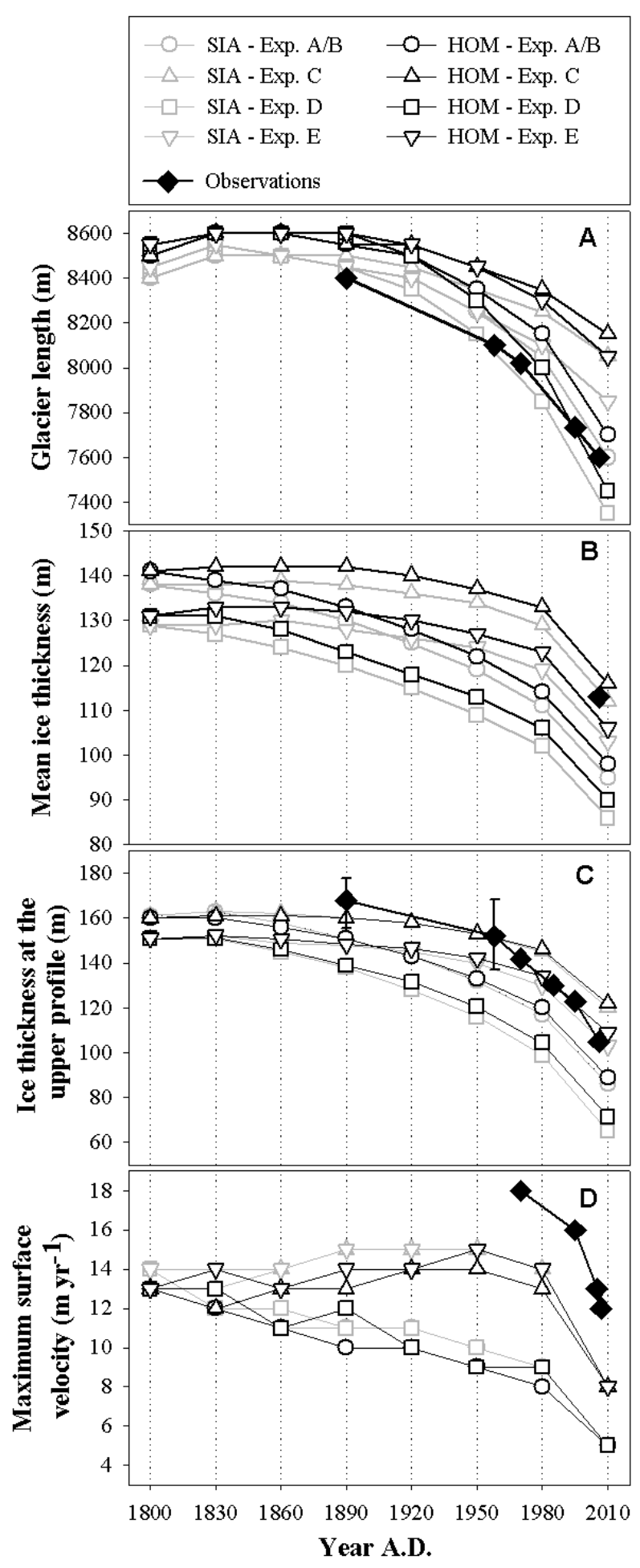

Fig. 6. Time series of glacier response according to the different experiments. Observations are represented by a large black diamonds. Note that results of experiments A and B are the same results and curves are overlapping. (A) glacier length evolution; (B) mean ice thickness evolution; (C) ice thickness evolution at the upper transverse profile; (D) maximum surface velocity. standard experiment. Figure 6 shows the time dependent evolution of McCall Glacier as simulated according to the different experiments with both HOM and SIA models. Available observations are also plotted on the graph to facilitate comparison and validation.

All simulations show a distinct retreat of McCall Glacier for the beginning of the 20th Century and show an accelerated retreat from the second half of the 20th Century, mainly driven by the increase change in the ELA rate. Prior to 1890, glacier retreat is negligible (Fig. 6a). Overall, experiments including internal accumulation (Exp. C and E) clearly underestimate the observed retreat while those including only basal sliding (Exp. D) evidently overestimate glacier retreat. The best fit is obtained by the standard experiment (Exp. B).

Glacier ice thickness variations are validated against field measurements (Pattyn et al., 2008 ${ }^{1}$ ), and are characterized by a general tendency of decrease with time. However, experiment $\mathrm{C}$ shows a slight increase in ice thickness prior to recent deglaciation, and gives the most realistic value in terms of present-day mean ice thickness (Fig. 6b). Results of experiments including internal accumulation (Exp. C and E) are also more accurate when compared to measurements of the upper transverse profile (Fig. 6c).

Finally, model simulations are compared to surface ice velocity measurements carried out at different periods in time (Fig. 6d). Here, results are in concordance with the above analysis, i.e. that the experiments including internal accumulation (C and $\mathrm{E}$ ) agree the best with observed values, but remain underestimated as a whole.

To summarize, the recent retreat history of McCall Glacier can be simulated taking into account the evolution of the ELA (and accelerated ELA increase after the 1970s) as well as internal accumulation. The effect of higher surface temperature on the thermomechanical behavior is of minor importance, as A and B show similar results. Internal accumulation leads to thicker ice and higher surface velocities compared to the standard experiment while basal sliding seems to give reverse effects. Both HOM and SIA models give similar results, albeit that the HOM velocities are generally lower and as a result ice thickness being slightly higher (Fig. 6). The lower velocity field according to the HOM is due to longitudinal stress coupling that smooths out local variability in the flow field (Pattyn et al., 2005).

Figure 7 compares the simulated ice thicknesses for present situation for the different HOM experiments and field observations along the longitudinal flowline. Ice thickness is overestimated by all simulations for the first two kilometers and underestimated between $\mathrm{km} 2$ and 5. Experiments B and E seem to be the most accurate while D underestimates the ice thickness (as can be concluded from Fig. 6b and 6c). Experiment $\mathrm{C}$, which includes internal accumulation, is slightly overestimating ice thickness.

The simulated velocity field along the modeled flowline is compared to field observations as well. Figure 8 displays the surface velocity along the central flowline according to 


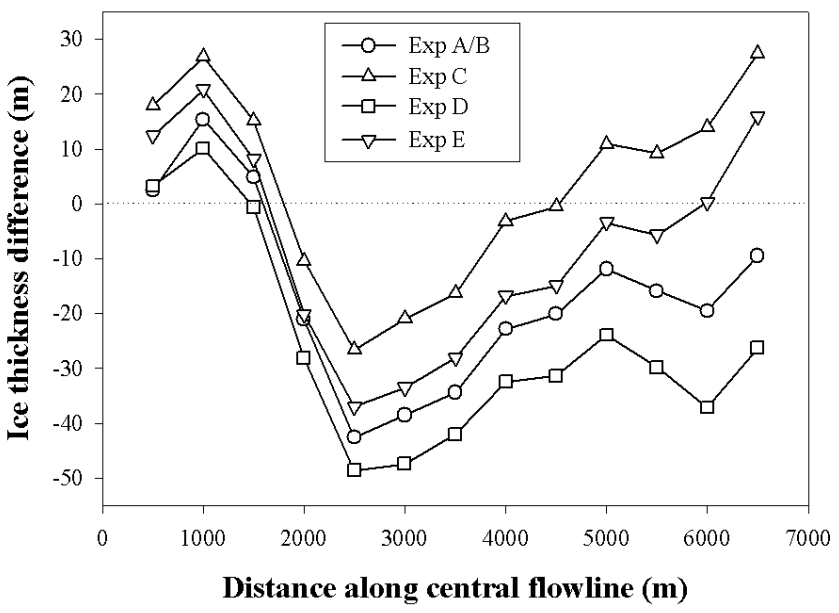

Fig. 7. Present-day ice thickness difference between the different HOM experiments and field observations along the longitudinal profile of the glacier.

the different HOM experiments and the measured surface velocities for three different time steps, i.e. 1970, 1995 and 2005. All results point to simulated surface velocities being underestimated between $\mathrm{km} 2$ and 5 of the flowline. This corresponds to the area of where ice thickness has been underestimated (Fig. 7). However, experiments $\mathrm{C}$ and $\mathrm{E}$ give accurate values at the beginning and the end of the profile while those which are not including internal accumulation show lower values. Once more, internal accumulation seems necessary to explain the historical evolution and the current state of McCall Glacier.

\section{Discussion}

According to the sensitivity experiments, the retreat history of McCall Glacier is dominated by the interplay between ELA variations (and accelerated ELA increase) and internal accumulation rate. Internal accumulation is difficult to estimate as there is an obvious lack of direct measurements on McCall Glacier. However, its parameterization (Table 2) follows the estimates made by Trabant and Mayo (1985) and Rabus and Echelmeyer (1998) and is especially important in the simulation of the historical retreat (prior to 2005). For the predictive simulations, the accumulation area becomes so small that the internal accumulation has much less effect on the overall glacier behaviour. The glacier thinning rate during this period is therefore comparable to that of the other experiments. Internal accumulation has often been disregarded, as it is not measured using conventional mass balance measuring techniques. For instance, Schneider and Jansson (2004) estimate internal accumulation as being 3$5 \%$ of the annual accumulation on Storglaciären, Sweden. $30 \%$ was found to be due to refreezing and percolating meltwater in spring and $70 \%$ due to refreezing of retained cap-

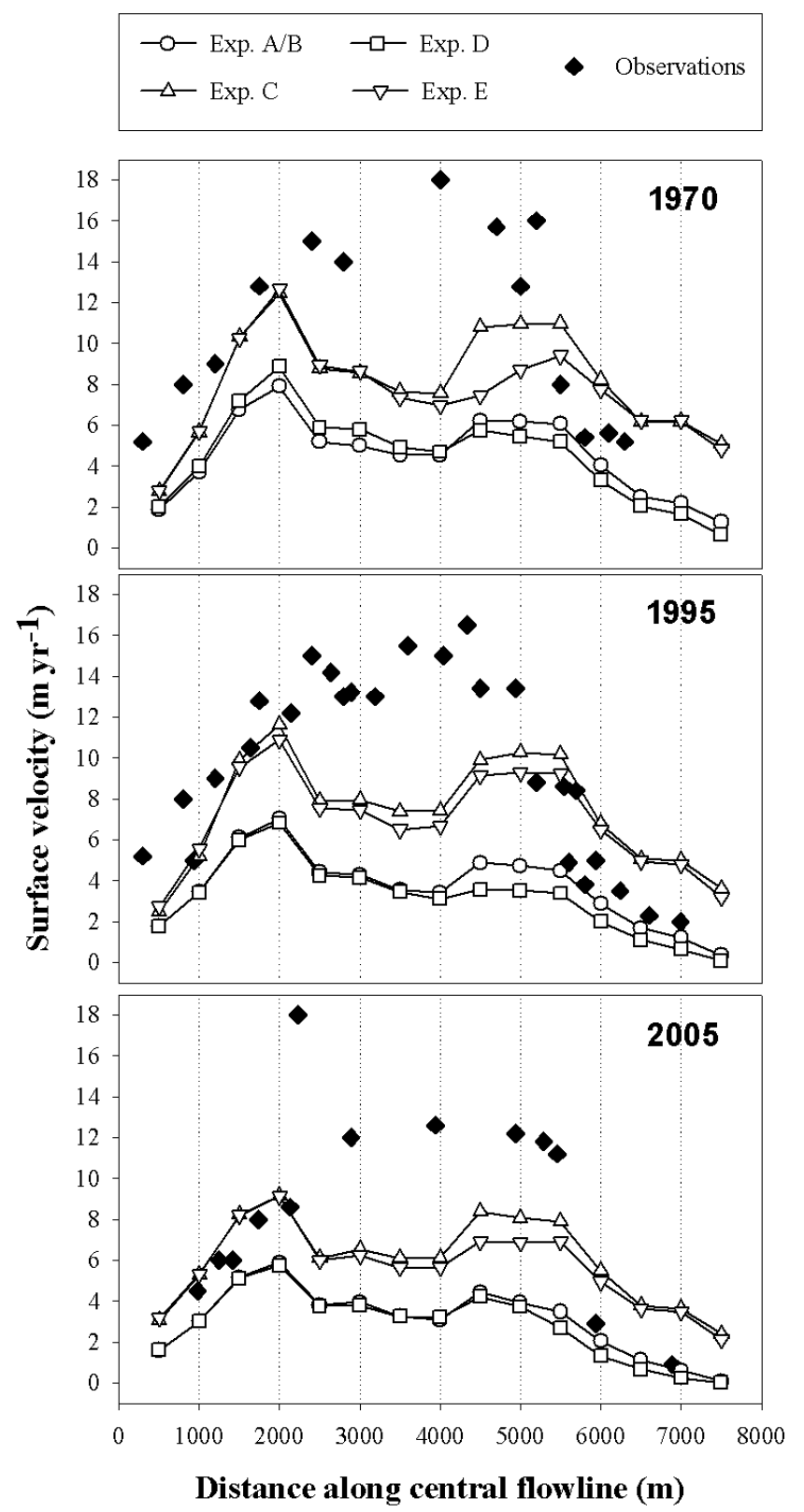

Fig. 8. Surface velocity along the flowline according to the different HOM experiments and observations for 1970, 1995 and 2005. Field measurements are from Rabus and Echelmeyer (1998) and Nolan et al. (2005).

illary water in firn pores during winter (Schneider and Jansson, 2004). Trabant and Mayo (1985) developed methods to estimate internal accumulation of several Alaskan glaciers and found values of $40-50 \%$ of the net accumulation for the period 1968-1972. Moreover, processes linked to internal accumulation, like its influence on the thermal regime (Blatter, 1987), are poorly known although they are quite important in polythermal glaciers. For example, latent-heat release, linked to the refreezing of meltwater, increases the 
Table 2. Evolution of accumulation parameters with time. The accumulation area is inferred from the topographic data (Fig. 1), while $a_{s}$ (surface accumulation), $a_{i}$ (internal accumulation) and $a$ (total accumulation) are the values used in the HOM experiments. Note the increasing part of internal accumulation with time and the reduction of the Accumulation Area Ratio (AAR).

\begin{tabular}{ccccccc}
\hline $\begin{array}{c}\text { Year } \\
\text { A.D. }\end{array}$ & $\begin{array}{c}\text { ELA } \\
\mathrm{m}\end{array}$ & $\begin{array}{c}a \text { area } \\
\mathrm{km}^{2}\end{array}$ & $\begin{array}{c}a_{s} \\
\mathrm{~m} \mathrm{a}^{-1}\end{array}$ & $\begin{array}{c}a_{i} \\
\mathrm{~m} \mathrm{a}^{-1}\end{array}$ & $\begin{array}{c}a_{i} / a \\
\%\end{array}$ & AAR \\
\hline 1810 & 1905 & 4.01 & 0.43 & 0.18 & 29.58 & 0.57 \\
1890 & 1966 & 3.54 & 0.38 & 0.25 & 39.80 & 0.50 \\
1950 & 2013 & 3.21 & 0.34 & 0.31 & 48.05 & 0.46 \\
1970 & 2038 & 3.08 & 0.32 & 0.34 & 51.24 & 0.45 \\
1980 & 2138 & 2.03 & 0.23 & 0.43 & 64.70 & 0.33 \\
1990 & 2234 & 1.01 & 0.15 & 0.60 & 79.68 & 0.20 \\
2000 & 2329 & 0.28 & 0.07 & 1.98 & 96.52 & 0.06 \\
\hline
\end{tabular}

temperatures in the accumulation area. Blatter and Hutter (1991) concluded that the polythermal structure of glaciers can be explained by the advection of this warmer ice in the upper ablation zone. The associated increase of basal ice temperatures can then be sufficient to reach pressure melting point and allow for basal sliding.

Another factor that hampers the quality of the simulations is the three-dimensional nature of McCall Glacier. Although the 3-D effect is taken into account by the introduction of a width factor in the continuity Eq. (4), the accumulation area consists of three cirques (UC, MC and LC, see Fig. 1), of which two of them are important contributors to the mass balance (UC and LC), albeit that the accumulation area is largest for the UC. During the LIA, they were all part of the accumulation area. At present, the LC, which represents a surface of $1.24 \mathrm{~km}^{2}$ for a total glacier surface of about $6 \mathrm{~km}^{2}$, became part of the ablation area as a consequence of the accelerated ELA increase since the 1970s. The AAR, which was about 0.45 in the $1970 \mathrm{~s}$, is below 0.1 at present. This is probably the reason why McCall Glacier endured an accelerated retreat after the 1990s, linked to a decreasing surface mass balance. The process of accelerated AAR reduction is implicitly taken into account through accelerated ELA increase. However, neglecting the LC in the model calculations has probably its effects on the mismatch in ice thickness and surface velocities between $\mathrm{km} 2$ and 5 (Figs. 7 and 8). This area corresponds to the zone of convergence between $\mathrm{LC}$ and UC (Fig. 1). Inclusion of the LC in the determination of the width parameter $W$ did not alter this mismatch, but led to an overestimation of the divergent nature of the ice flux in the accumulation area. However, future three-dimensional model simulations should improve the retreat estimates.

An apparent feature of the model simulations is the good agreement between both HOM and SIA models. Pattyn et al. (2005) demonstrated that for diagnostic experiments inclusion of longitudinal stress gradients is necessary, as such stresses must develop given that the surface elevation is fixed and large surface slopes lead to unrealistic velocities with an SIA model. However, when the surface is allowed to relax in a time-dependency, these differences become less apparent. This is especially true for a smooth bedrock topography (as is the case for McCall Glacier) or when basal sliding is not the dominant contributor to the ice flow. Similar findings were obtained by Pattyn (2002) and Leysinger Vieli and Gudmundsson (2004).

\section{Conclusions}

McCall Glacier is a sensitive glacier to recent climate warming, and has therefore long been considered as a good indicator of climate change in the Arctic. By using a numerical model, we tried to simulate the historic front variations of this polythermal valley glacier since the Little Ice Age. The model experiments are capable of simulating the recent retreat history of the glacier in a realistic way. The experiments confirm that McCall Glacier is essentially sensitive to mass balance perturbations, and indicates an accelerated retreat since the 1990s due to an an accelerated increasing of the ELA (associated with an important reduction in accumulation area). Apart from ELA variations, internal accumulation is an essential factor to explain the current state of the glacier and to counterbalance accelerated glacier thinning. This process seems also to be necessary to maintain the temperate basal layer of the lower part glacier of McCall Glacier. In view of the rather smooth bedrock topography in the glacier basin as well as limited basal sliding, the shallowice glacier model results are in accord with the higher-order model calculations.

Acknowledgements. This research forms part of the US National Science Foundation's Freshwater Initiative (OPPARCSS) and is partly financed by a FWO-Vlaanderen "Krediet aan navorsers" project. The authors are indebted to all members of the 2003, 2005 and 2006 McCall field parties.

Edited by: J. O. Hagen

\section{References}

Blatter, H.: On the Thermal Regime of an Arctic Valley Glacier: a Study of White Glacier, Axel Heiberg Island, N.W.T., Canada, J. Glaciol., 33, 200-211, 1987.

Blatter, H. and Hutter, K.: Polythermal Conditions in Arctic Glaciers, J. Glaciol., 37, 261-269, 1991.

Huybrechts, P.: The Antarctic Ice Sheet and Environmental Change: a Three-Dimensional Modelling Study, Berichte für Polarforschung, 99, 1-241, 1992.

IPCC: Contribution of Working Group I to the Fourth Assessment Report of the Intergovernmental Panel on Climate Change, in: Climate Change 2007: The Physical Science Basis., edited by: Solomon, S., Qin, D., Manning, M., Chen, Z., Marquis, M., 
Averyt, K., Tignor, M., and Miller, H., p. 996, Cambridge University Press, Cambridge, United Kingdom and New York, NY, USA, 2007.

Leysinger Vieli, G. J.-M. C. and Gudmundsson, G. H.: On estimating length fluctuations of glaciers caused by changes in climatic forcing, J. Geophys. Res., 109, F01007, doi:10.1029/2003JF000027, 2004.

Nolan, M., Arendt, A., Rabus, B., and Hinzman, L.: Volume change of McCall Glacier, Arctic Alaska, from 1956 to 2003, Ann. Glaciol., 42, 409-416, 2005.

Paterson, W.: The Physics of Glaciers, Oxford, Pergamon Press, 3rd edn., 1994.

Pattyn, F.: Transient Glacier Response with a Higher-Order Numerical Ice-Flow Model, J. Glaciol., 48, 467-477, 2002.

Pattyn, F., Nolan, M., Rabus, B., and Takahashi, S.: Localized basal motion of a polythermal Arctic glacier: McCall Glacier, Alaska, USA, Ann. Glaciol., 40, 47-51, 2005.
Rabus, B. and Echelmeyer, K.: The Mass Balance of McCall Glacier, Brooks Range, Alaska, U.S.A.; its Regional relevance and Implications for Climate Change in the Arctic, J. Glaciol., 44, 333-351, 1998.

Rabus, B. and Echelmeyer, K.: Increase of $10 \mathrm{~m}$ Ice Temperature: Climate Warming or Glacier Thinning?, J. Glaciol., 48, 279-286, 2002.

Rabus, B., Echelmeyer, K., Trabant, D., and Benson, C.: Recent Changes of McCall Glacier, Alaska, Ann. Glaciol., 21, 231-239, 1995.

Schneider, T. and Jansson, P.: Internal Accumulation in Firn and its Significance for the Mass Balance of Storglaciären, Sweden, J. Glaciol., 50, 25-34, 2004.

Shapiro, N. and Ritzwoller, M.: Inferring Surface Heat Flux Distributions Guided by a Global Seismic Model: Particular Application to Antarctica, Earth Planet. Sci. Lett., 223, 213-224, 2004.

Trabant, D. and Mayo, L.: Estimation and Effects of Internal Accumulation on Five Glaciers in Alaska, Ann. Glaciol., 6, 113-117, 1985. 